Acta Crystallographica Section B

Structural

Science

ISSN 0108-7681

Stephen A. Moggach, ${ }^{\mathrm{a} *}$ David R. Allan, ${ }^{a}$ Simon Parsons ${ }^{\mathrm{a}}$ and Lindsay Sawyer

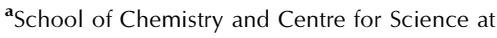
Extreme Conditions, The University of Edinburgh, King's Buildings, West Mains Road, Edinburgh EH9 3J J, Scotland, and ${ }^{\mathbf{b}}$ Institute for Cell and Molecular Biology and Centre for Science at Extreme Conditions, The University of Edinburgh, King's Buildings, West Mains Road, Edinburgh EH9 3JR, Scotland

Correspondence e-mail: s.moggach@ed.ac.uk

\title{
Effect of pressure on the crystal structure of $a$ - glycylglycine to 4.7 GPa; application of Hirshfeld surfaces to analyse contacts on increasing pressure
}

The crystal structure of $\alpha$-glycylglycine ( $\alpha$-GLYGLY) has been determined at room temperature at pressures between 1.4 and $4.7 \mathrm{GPa}$. The structure can be considered to consist of layers. The arrangement of molecules within each layer resembles the antiparallel $\beta$-sheet motif observed in proteins, except that in $\alpha$-GLYGLY the motif is constructed through $\mathrm{NH}$... O hydrogen bonds rather than covalent amide links. Compression of $\alpha$-GLYGLY proceeds via the reduction in void sizes. Voids close in such a way as to decrease the distances of stabilizing interactions such as hydrogen bonds and dipolar contacts. The largest reductions in interaction distances tend to occur for those contacts which are longest at ambient pressure. These longer interactions are formed between the $\beta$-sheet-like layers, and the largest component of the strain tensor lies in the same direction. The $\mathrm{N}$...O distance in one NH. . O hydrogen bond measures 2.624 (9) $\AA$ at $4.7 \mathrm{GPa}$. This is very short for this kind of interaction and the crystal begins to break up above $5.4 \mathrm{GPa}$, presumably as the result of a phase transition. The changes that occur have been analysed using Hirshfeld surfaces. Changes in the appearance of these surfaces enable rapid assessment of the structural changes that occur on compression.

\section{Introduction}

Glycylglycine (GLYGLY) is the simplest dipeptide. It is composed of two glycine residues and in the solid state it exists in three different polymorphic forms. These polymorphs were designated $\alpha, \beta$ and $\gamma$ by Bernal (1931). A preliminary investigation made by Bernal (1931) found that all three polymorphs could be grown simultaneously from the same mother liquor by slow evaporation from concentrated solutions in $n$-propyl alcohol and water. It was found in this study that the plate-like $\alpha$ form predominates, with numerous recrystallizations required to obtain crystals of the $\beta$ and $\gamma$ polymorphs. No report of the $\gamma$ polymorph has appeared since Bernal's publication in 1931, while no report of the $\beta$ polymorph has appeared since Hughes \& Moore (1949). The $\alpha$ GLYGLY polymorph, however, has been studied more recently by both neutron and X-ray diffraction; the most recent structure was reported by Kvick et al. (1977) in a deformation electron-density study.

Early work on the compressibility of hydrogen-bonded solids was carried out by Katrusiak and co-workers (for example, Katrusiak \& Nelmes, 1986; Katrusiak, 1990a,b, 2004). The responses of the crystal structures of several amino acids to high hydrostatic pressure have been described recently (Dawson et al., 2005; Moggach, Allan, Lozano-Casal \& Parsons, 2005; Moggach, Allan, Morrison, Parsons \& Sawyer, 2005; Moggach, Allan, Parsons, Sawyer \& Warren,
Received 14 November 2005 Accepted 15 December 2005
(C) 2006 International Union of Crystallography Printed in Great Britain - all rights reserved

.

(1)


2005; Boldyreva et al., 2004, 2005). The behaviour of the distances characterizing intermolecular interactions was rationalized by studying the way in which interstitial voids deform under pressure. It was notable that compression continued until the minimum distance, as observed for a specific interaction (e.g. the $\mathrm{N} \cdots \mathrm{O}$ distance in an $\mathrm{N}-\mathrm{H} \cdots \mathrm{O}$ hydrogen bond) under ambient pressure, had been reached (i.e. super-short hydrogen bonds are apparently not formed up to $c a 10 \mathrm{GPa}$ ) and it was at this point that a phase transition occurred. However, the extent to which our observations have any generality still needs to be established and we now extend this work to the $\alpha$-polymorph of GLYGLY. Although some studies have appeared recently on the behaviour of proteins under non-ambient pressure conditions, for example on cubic Cowpea mosaic virus crystals (Girard et al., 2005), this is the first study in which the crystal structure of a dipeptide has been examined at high pressure. ${ }^{1}$<smiles>[NH3+]CC(=O)NCC(=O)[O-]</smiles>

(I)

\section{Experimental}

\subsection{Crystal growth and high-pressure crystallography}

Crystals of $\alpha$-GLYGLY were grown by slow diffusion of ethanol into a concentrated aqueous solution of GLYGLY ( $99 \%$ ) obtained from Sigma (catalogue number G, 1002). One block-shaped crystal of dimensions $0.1 \times 0.2 \times 0.2 \mathrm{~mm}^{3}$ was selected and loaded into a Merrill-Bassett diamond-anvil cell (Merrill \& Bassett, 1974). The cell had a half-opening angle of $40^{\circ}$ and was equipped with $600 \mu \mathrm{m}$ culets and a tungsten gasket. A 4:1 mixture of methanol and ethanol was used as a hydrostatic medium. A small ruby chip was also loaded into the cell as the pressure calibrant, with the ruby fluorescence method used to measure the pressure (Piermarini et al., 1975).

\subsection{Data collection, reduction and refinement}

A hemisphere of reflections was collected at ambient temperature and pressure in order to provide a comparison with data collected at increasing pressures during the pressure study. All high-pressure data were collected at ambient temperature (see below). Diffraction data were collected (Bruker-Nonius, 2002) on a Bruker SMART APEX diffractometer with graphite-monochromated Mo $K \alpha$ radiation $(\lambda=$ $0.71073 \AA)$. These data were integrated using the program SAINT (Bruker-Nonius, 2004a) and an absorption correction was performed with the program SADABS (Sheldrick, 2004).

\footnotetext{
${ }^{1}$ Supplementary data for this paper are available from the IUCr electronic archives (Reference: GP5004). Services for accessing these data are described at the back of the journal.
}

The $\alpha$-GLYGLY coordinates of Kvick et al. (1977) were refined against these data to yield a conventional $R$ factor of 0.0488 for 1164 data with $I>2 \sigma(I)$. A listing of crystal and refinement data is given in Table 1 . The molecular structure and numbering scheme used is shown in Fig. 1.

High-pressure diffraction data were collected on a kappageometry, Bruker APEX II diffractometer with graphitemonochromated Mo $K \alpha$ radiation $(\lambda=0.71073 \AA$; BrukerNonius, 2004b). Data collection procedures followed those of Dawson et al. (2004). Integrations were carried out using the program SAINT, and absorption corrections in a two-stage process with the programs SHADE (Parsons, 2004) and $S A D A B S$ (Sheldrick, 2004). Data collections were taken in approximately $1.0 \mathrm{GPa}$ steps from $1.4 \mathrm{GPa}$ up to a final pressure of $5.3 \mathrm{GPa}$.

Refinements were carried out starting from the coordinates determined at ambient pressure. Minimization was against $|F|^{2}$ using all data (CRYSTALS; Betteridge et al., 2003). Owing to the low completeness of the data-sets, all 1,2 and 1,3 distances were restrained to values observed in the ambient pressure structure. Specifically, the restraints were as follows: distances (̊): $\mathrm{N} 1-\mathrm{C} 11.473(5), \mathrm{C} 1-\mathrm{C} 21.511$ (5), C2-O1 1.238 (5), $\mathrm{C} 2-\mathrm{N} 21.330$ (5), N2-C3 1.450 (5), C3-C4 1.513 (5), C4O3 1.240 (5), $\mathrm{C} 4-\mathrm{O} 21.255$ (5); angles $\left(^{\circ}\right)$ : $\mathrm{N} 1-\mathrm{C} 1-\mathrm{C} 2109$ (1), $\mathrm{C} 1-\mathrm{C} 2-\mathrm{O} 1120$ (1), $\mathrm{O} 1-\mathrm{C} 2-\mathrm{N} 2123$ (1), N2-C2-C1 116 (1), C4-C3-N2 112 (1), C3-C4-O3 115 (1), C3-C4O2 118 (1), O2-C4-O3 126 (1), C2-N2-C3 121 (1). All non-H atoms were refined with isotropic displacement parameters. Owing to the poor quality of the data set collected at $5.4 \mathrm{GPa}$, the data collected to $4.7 \mathrm{GPa}$ were used for structural comparison to the ambient temperature and pressure structure. Listings of crystal and refinement data are given in Table 1.

Crystal structures were visualized using the programs DIAMOND (Crystal Impact, 2004) and XP (Sheldrick, 1997). Analyses were carried out using PLATON (Spek, 2003), as incorporated in the WIN-GX suite (Farrugia, 1999). Searches of the Cambridge Database (Allen, 2002) were performed with the program CONQUEST (Allen \& Motherwell, 2002) and Version 5.26 of the database with updates up to August 2005. Hirshfeld surface analysis was performed using the program CrystalExplorer (Wolff et al., 2005).

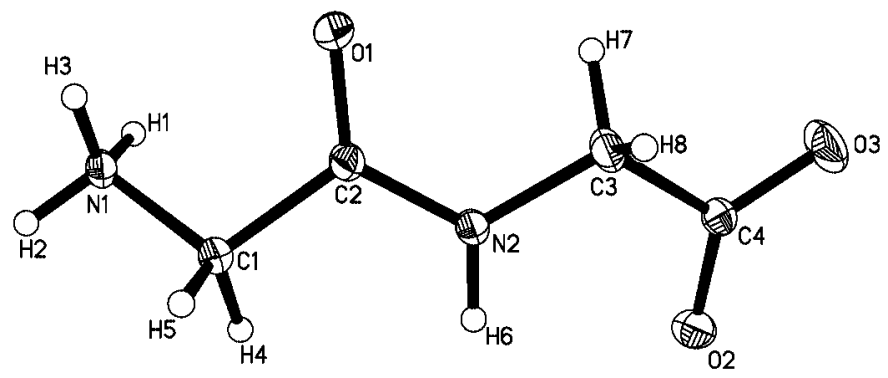

Figure 1

The molecular structure of GLYGLY at ambient temperature and pressure showing atom labelling. Ellipsoids are drawn at the $30 \%$ probability level, $\mathrm{H}$ atoms are drawn as spheres of arbitrary radius. 
Table 1

Crystallographic data for $\alpha$-GLYGLY at ambient temperature between 0 and $4.7 \mathrm{GPa}$.

\begin{tabular}{|c|c|c|c|c|c|}
\hline Pressure (GPa) & 0 & 1.4 & 3.0 & 3.7 & 4.7 \\
\hline \multicolumn{6}{|l|}{ Crystal data } \\
\hline Chemical formula & $\mathrm{C}_{4} \mathrm{H}_{8} \mathrm{~N}_{2} \mathrm{O}_{3}$ & $\mathrm{C}_{4} \mathrm{H}_{8} \mathrm{~N}_{2} \mathrm{O}_{3}$ & $\mathrm{C}_{4} \mathrm{H}_{8} \mathrm{~N}_{2} \mathrm{O}_{3}$ & $\mathrm{C}_{4} \mathrm{H}_{8} \mathrm{~N}_{2} \mathrm{O}_{3}$ & $\mathrm{C}_{4} \mathrm{H}_{8} \mathrm{~N}_{2} \mathrm{O}_{3}$ \\
\hline$M_{r}$ & 132.12 & 132.12 & 132.12 & 132.12 & 132.12 \\
\hline $\begin{array}{l}\text { Cell setting, space } \\
\text { group }\end{array}$ & Monoclinic, $P 2_{1} / c$ & Monoclinic, $P 2_{1} / c$ & Monoclinic, $P 2_{1} / c$ & Monoclinic, $P 2_{1} / c$ & Monoclinic, $P 2_{1} / c$ \\
\hline$a, b, c(\AA)$ & $\begin{array}{l}8.1233(18), 9.554(2) \\
7.8224(17)\end{array}$ & $\begin{array}{l}7.6428(3), 9.3800(4), \\
\quad 7.6505(5)\end{array}$ & $\begin{array}{l}7.4304(4), 9.2896(7), \\
7.5943(9)\end{array}$ & $\begin{array}{l}7.3100(15), 9.232(2), \\
\quad 7.550(3)\end{array}$ & $\begin{array}{l}7.2437(8), 9.2083(13) \\
\quad 7.5328(17)\end{array}$ \\
\hline$\beta\left({ }^{\circ}\right)$ & $107.596(4)$ & $103.882(4)$ & $102.465(7)$ & $101.51(3)$ & $101.214(14)$ \\
\hline$V\left(\AA^{3}\right)$ & $578.7(2)$ & $532.44(5)$ & $511.84(8)$ & $499.3(3)$ & $492.86(14)$ \\
\hline$Z$ & 4 & 4 & 4 & 4 & 4 \\
\hline$D_{x}\left(\mathrm{Mg} \mathrm{m}^{-3}\right)$ & 1.516 & 1.648 & 1.714 & 1.758 & 1.780 \\
\hline Radiation type & Mo $K \alpha$ & Mo $K \alpha$ & Mo $K \alpha$ & $\operatorname{Mo} K \alpha$ & Mo $K \alpha$ \\
\hline $\begin{array}{l}\text { No. of reflections for } \\
\text { cell parameters }\end{array}$ & 1501 & 1234 & 1235 & 1211 & 1070 \\
\hline$\theta$ range $\left({ }^{\circ}\right)$ & $5-56$ & $5-52$ & $6-53$ & $6-53$ & $6-52$ \\
\hline$\mu\left(\mathrm{mm}^{-1}\right)$ & 0.13 & 0.14 & 0.15 & 0.15 & 0.15 \\
\hline Temperature (K) & 293 & 293 & 293 & 293 & 293 \\
\hline Crystal form, colour & Block, colourless & Block, colourless & Block, colourless & Block, colourless & Block, colourless \\
\hline Crystal size (mm) & $0.60 \times 0.36 \times 0.12$ & $0.20 \times 0.20 \times 0.10$ & $0.20 \times 0.20 \times 0.10$ & $0.20 \times 0.20 \times 0.10$ & $0.20 \times 0.20 \times 0.10$ \\
\hline \multicolumn{6}{|l|}{ Data collection } \\
\hline Diffractometer & Bruker APEX & Bruker APEX II & Bruker APEX II & Bruker APEX II & Bruker APEX II \\
\hline Data collection method & $\omega$ scans & $\omega$ scans & $\omega$ scans & $\omega$ scans & $\omega$ scans \\
\hline Absorption correction & $\begin{array}{l}\text { Multi-scan (based on } \\
\text { symmetry-related } \\
\text { measurements) }\end{array}$ & $\begin{array}{l}\text { Multi-scan (based on } \\
\text { symmetry-related } \\
\text { measurements) }\end{array}$ & $\begin{array}{l}\text { Multi-scan (based on } \\
\text { symmetry-related } \\
\text { measurements) }\end{array}$ & $\begin{array}{l}\text { Multi-scan (based on } \\
\text { symmetry-related } \\
\text { measurements) }\end{array}$ & $\begin{array}{l}\text { Multi-scan (based on } \\
\text { symmetry-related } \\
\text { measurements) }\end{array}$ \\
\hline$T_{\min }$ & 0.86 & 0.85 & 0.86 & 0.84 & 0.75 \\
\hline$T_{\max }$ & 0.98 & 0.99 & 0.99 & 0.99 & 0.98 \\
\hline $\begin{array}{l}\text { No. of measured, inde- } \\
\text { pendent and } \\
\text { observed reflections }\end{array}$ & $3696,1390,1164$ & $2911,471,360$ & $2733,451,348$ & $2678,435,332$ & $2669,437,318$ \\
\hline $\begin{array}{l}\text { Criterion for observed } \\
\text { reflections }\end{array}$ & $I>2.00 \sigma(I)$ & $I>2.00 \sigma(I)$ & $I>2.00 \sigma(I)$ & $I>2.00 \sigma(I)$ & $I>2.00 \sigma(I)$ \\
\hline Completeness (\%) & 99.8 & 45.4 & 45.2 & 45.8 & 45.8 \\
\hline$R_{\text {int }}$ & 0.027 & 0.052 & 0.048 & 0.048 & 0.052 \\
\hline$\theta_{\max }\left({ }^{\circ}\right)$ & 28.7 & 27.2 & 26.8 & 26.9 & 27.2 \\
\hline Range of $h, k, l$ & $\begin{array}{l}-10 \Rightarrow h \Rightarrow 6 \\
-11 \Rightarrow k \Rightarrow 12 \\
-10 \Rightarrow l \Rightarrow 10\end{array}$ & $\begin{array}{l}-9 \Rightarrow h \Rightarrow 9 \\
-11 \Rightarrow k \Rightarrow 11 \\
-5 \Rightarrow l \Rightarrow 5\end{array}$ & $\begin{array}{l}-9 \Rightarrow h \Rightarrow 8 \\
-10 \Rightarrow k \Rightarrow 10 \\
-5 \Rightarrow l \Rightarrow 5\end{array}$ & $\begin{array}{l}-9 \Rightarrow h \Rightarrow 8 \\
-10 \Rightarrow k \Rightarrow 10 \\
-5 \Rightarrow l \Rightarrow 5\end{array}$ & $\begin{array}{l}-9 \Rightarrow h \Rightarrow 8 \\
-10 \Rightarrow k \Rightarrow 10 \\
-5 \Rightarrow l \Rightarrow 5\end{array}$ \\
\hline \multicolumn{6}{|l|}{ Refinement } \\
\hline Refinement on & $F^{2}$ & $F^{2}$ & $F^{2}$ & $F^{2}$ & $F^{2}$ \\
\hline$\underset{S}{R\left[F^{2}>2 \sigma\left(F^{2}\right)\right], w R\left(F^{2}\right)}$ & $0.049,0.140,1.01$ & $0.076,0.198,1.05$ & $0.075,0.189,1.03$ & $0.068,0.163,1.04$ & $0.072,0.187,1.03$ \\
\hline No. of reflections & 1385 & 455 & 434 & 419 & 422 \\
\hline No. of parameters & 82 & 37 & 37 & 37 & 37 \\
\hline $\mathrm{H}$-atom treatment & Not refined & Not refined & Not refined & Not refined & Not refined \\
\hline Weighting scheme & $\begin{aligned} w & =1 /\left[\sigma^{2}\left(F^{2}\right)+(0.08 P)^{2}\right. \\
& +0.11 P], \text { where } P= \\
& {\left[\max \left(F_{o}^{2}, 0\right)+2 F_{c}^{2}\right] / 3 }\end{aligned}$ & $\begin{array}{c}w=1 /\left[\sigma^{2}\left(F^{2}\right)+(0.08 P)^{2}\right. \\
\quad+2.28 P], \text { where } P= \\
\quad\left[\max \left(F_{o}^{2}, 0\right)+2 F_{c}^{2}\right] / 3\end{array}$ & $\begin{aligned} w & =1 /\left[\sigma^{2}\left(F^{2}\right)+(0.08 P)^{2}\right. \\
& +1.99 P], \text { where } P= \\
& {\left[\max \left(F_{o}^{2}, 0\right)+2 F_{c}^{2}\right] / 3 }\end{aligned}$ & $\begin{aligned} w & =1 /\left[\sigma^{2}\left(F^{2}\right)+(0.05 P)^{2}\right. \\
& +2.18 P], \text { where } P= \\
& {\left[\max \left(F_{o}^{2}, 0\right)+2 F_{c}^{2}\right] / 3 }\end{aligned}$ & $\begin{aligned} w & =1 /\left[\sigma^{2}\left(F^{2}\right)+(0.08 P)^{2}\right. \\
& +2.23 P], \text { where } P= \\
& {\left[\max \left(F_{o}^{2}, 0\right)+2 F_{c}^{2}\right] / 3 }\end{aligned}$ \\
\hline$(\Delta / \sigma)_{\max }$ & $<0.0001$ & $<0.0001$ & $<0.0001$ & $<0.0001$ & $<0.0001$ \\
\hline$\Delta \rho_{\max }, \Delta \rho_{\min }\left(\mathrm{e} \AA^{-3}\right)$ & $0.28,-0.35$ & $0.40,-0.38$ & $0.38,-0.35$ & $0.31,-0.30$ & $0.35,-0.33$ \\
\hline
\end{tabular}

\section{Results}

\subsection{The structure of $\alpha$-GLYGLY at ambient temperature and pressure}

Hydrogen bonding in amino acids and peptides has been reviewed by Görbitz (1989) and by Jeffrey \& Maluszynska (1982). $\alpha$-GLYGLY crystallizes in its zwitterionic tautomer, with charged carboxyl and ammonium moieties, and the structure of GLYGLY is dominated by the formation of $\mathrm{NH}$... O hydrogen bonds, with five such interactions formed under ambient temperature and pressure conditions.

The hydrogen bond N2H6 . O 1 is formed between the $\mathrm{N}-$ $\mathrm{H}$ and $\mathrm{C}=\mathrm{O}$ moieties of neighbouring peptide groups and together with $\mathrm{N} 1 \mathrm{H} 3 \cdots \mathrm{O} 2$ form an $R_{2}^{2}(10)$ ring motif (Fig. 2a; Bernstein et al., 1995). Both of these hydrogen bonds are also involved in the formation of a larger $R_{4}^{4}(18)$ ring motif created with another of the $\mathrm{NH} \cdots \mathrm{O}$ hydrogen bonds, $\mathrm{N} 1 \mathrm{H} 2 \cdots \mathrm{O} 3$. The alternating pattern of $R_{2}^{2}(10)$ and $R_{4}^{4}(18)$ rings builds up

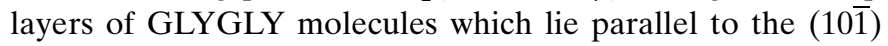
plane. The layers are reminiscent of the antiparallel $\beta$ sheets observed in protein structures ( $c f$. Figs. $2 a$ and $b$ ).

A bifurcated interaction, $\mathrm{N} 1 \mathrm{H} 1 \cdots \mathrm{O} 2 / \mathrm{O} 3$, connects the layers into a three-dimensional hydrogen-bonded array interacting between the layers (Fig. 3a). The shorter of the bifurcated hydrogen bonds, $\mathrm{N} 1 \mathrm{H} 1 \cdots \mathrm{O} 2$, forms an $R_{4}^{4}(12)$ ring motif with $\mathrm{N} 1 \mathrm{H} 2 \cdots \mathrm{O} 3$ (Fig. $4 a$ ), the hydrogen bond involved 
in the formation of the $R_{4}^{4}(18)$ ring motifs. Pairs of centrosymmetrically related $\mathrm{N} 1 \mathrm{H} 1 \cdots \mathrm{O} 2$ bonds also form $R_{2}^{2}(16)$ rings between the layers (Fig. $4 a$ ). The longer component of the bifurcated interaction, $\mathrm{N} 1 \mathrm{H} 1 \cdots \mathrm{O} 3$, is quite long at ambient pressure [3.196 (3) $\AA$ ], although it decreases in length on compression (Table 2). This bifurcated interaction, together with $\mathrm{N} 1 \mathrm{H} 2 \cdots \mathrm{O} 3$ and $\mathrm{N} 1 \mathrm{H} 3 \cdots \mathrm{O} 2$, forms an $R_{3}^{2}(6)$ ring motif which, like both the $R_{2}^{2}(16)$ and $R_{4}^{4}(12)$ ring motifs, acts between the layers (Fig. $3 a$ ).

To summarize, the three-dimensional hydrogen-bonding network within $\alpha$-GLYGLY can be described by reference to five $R$-type ring motifs. $R_{2}^{2}(10)$ and $R_{4}^{4}(18)$ ring motifs form layers, reminiscent of antiparallel $\beta$-sheet motifs in protein structures and lie parallel to the (101) planes, while $R_{4}^{4}(12)$, $R_{2}^{2}(16)$ and $R_{3}^{2}(6)$ ring motifs connect these layers into a threedimensional hydrogen-bonded network

In amino acid structures the presence of other interactions, particularly weaker $\mathrm{CH} \cdots \mathrm{O}$ interactions, are thought to be important for supporting moderate strength $\mathrm{NH} \cdots \mathrm{O}$ hydrogen bonds (Desiraju \& Steiner, 1999; Derewenda et al., 1995). We have discussed this recently in high-pressure studies of the crystal structures of polymorphs of glycine (Dawson et al., 2005) and serine (Moggach, Allan, Morrison, Parsons \& Sawyer, 2005). In $\alpha$-GLYGLY four $\mathrm{CH} \cdots \mathrm{O}$ interactions exist at ambient pressure and temperature. A pair of these, $\mathrm{C} 3 \mathrm{H} 8 \cdots \mathrm{O} 2 / \mathrm{O} 3$, constitutes a bifurcated hydrogen bond which acts between the layers to the carboxyl $\mathrm{O}$ atoms involved in the formation of the $R_{4}^{4}(18)$ ring motifs previously described (Fig. 3a). The third $\mathrm{CH} \cdots \mathrm{O}$ interaction, $\mathrm{C} 1 \mathrm{H} 5 \cdots \mathrm{O} 1$, is hydrogen bonded to the peptide carbonyl oxygen and also acts between the layers. The final $\mathrm{CH} \cdots \mathrm{O}$ hydrogen bond, $\mathrm{C} 1 \mathrm{H} 4 \cdots \mathrm{O} 1$, like $\mathrm{C} 1 \mathrm{H} 5 \ldots \mathrm{O} 1$, is also hydrogen bonded to the carbonyl oxygen, however, unlike $\mathrm{C} 1 \mathrm{H} 5 \cdots \mathrm{O} 1$, this hydrogen bond acts within the layers. The combination of both $\mathrm{C} 1 \mathrm{H} 4 \cdots \mathrm{O} 1$ and $\mathrm{C} 1 \mathrm{H} 5 \cdots \mathrm{O} 1$ produces an $R_{4}^{2}(8)$ ring motif between the layers (Fig. $5 a$ ). $\mathrm{C} 1 \mathrm{H} 4 \cdots \mathrm{O} 1$ is of particular interest, as it has been shown to have preferred directionality and length in parallel and antiparallel $\beta$ sheets with typical C. . O distances of 3.31 and $3.27 \AA$, respectively (Fabiola et al., 1997).

$\mathrm{C}=\mathrm{O} \cdots \mathrm{C}=\mathrm{O}$ interactions have been discussed in detail by Allen et al. (1998) and are thought to be important in the

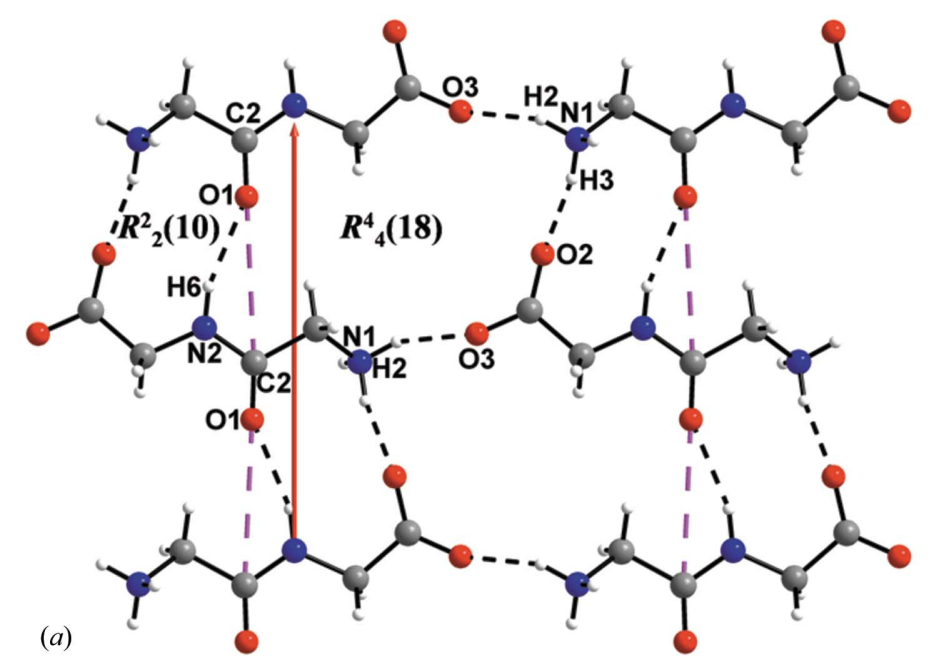

(b)
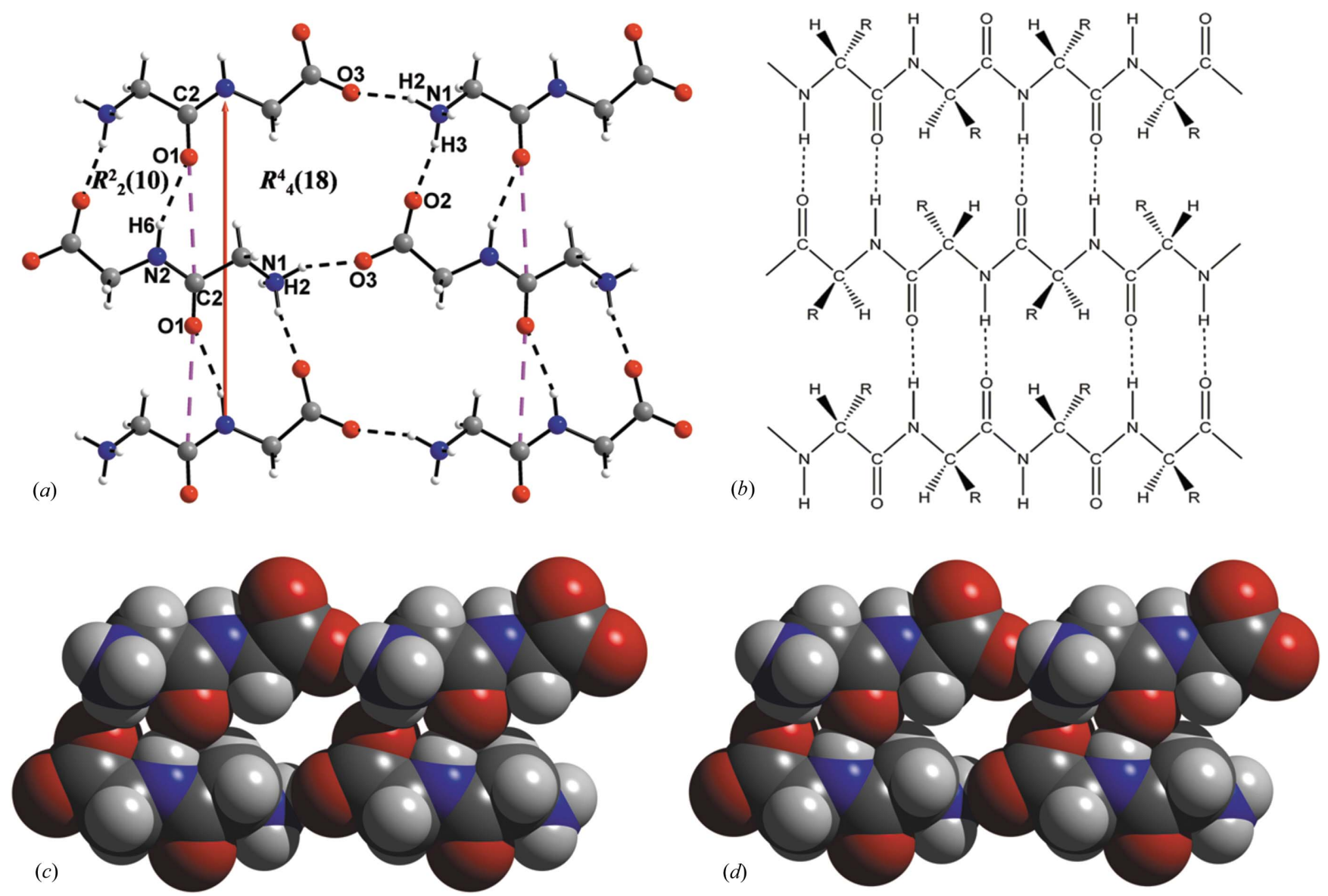

Figure 2

Ball-and-stick model showing $(a) R_{2}^{2}(10)$ and $R_{4}^{4}(18)$ ring motifs forming layers within $\alpha$-GLYGLY. The layers formed within the structure are also reminiscent of those of an antiparallel $\beta$ sheet motif $(b)$. Hydrogen bonds are drawn as black dotted lines, while weak $\mathrm{C}=\mathrm{O} \cdots \mathrm{C}=\mathrm{O}$ interactions are shown, only in $(a)$, as pink dotted lines. The second largest component of the strain tensor is drawn as a red arrow in $(a)$. Space-filling plots for $(c) \alpha-$ GLYGLY at ambient pressure and $(d)$ at $4.7 \mathrm{GPa}$ are shown. $(a),(c)$ and $(d)$ are viewed perpendicular to the $(10 \overline{1})$ plane. Note that voids in $R_{4}^{4}(18)$ and $R_{2}^{2}(10)$ ring motifs close up on increasing pressure. Colour scheme: $\mathrm{N}$ blue, $\mathrm{C}$ grey, $\mathrm{O}$ red and $\mathrm{H}$ white. 
Table 2

Hydrogen-bonding parameters $\left(\AA{ }^{\circ}\right)$ and $\mathrm{C}=\mathrm{O} \cdots \mathrm{C}=\mathrm{O}$ interactions in $\alpha$-GLYGLY.

The $\Delta$ column refers to the $4.7 \mathrm{GPa}$ distance subtracted from the distance at ambient pressure.

\begin{tabular}{|c|c|c|c|c|c|c|}
\hline Pressure (GPa) & 0 & 1.4 & 3.0 & 3.7 & 4.7 & $\Delta$ \\
\hline \multicolumn{7}{|c|}{ Hydrogen bonds formed between the $\beta$ sheet-like layers } \\
\hline $\begin{array}{c}\mathrm{N} 1 \mathrm{H} 1 \cdots \mathrm{O} 2^{\mathrm{i}} \\
\mathrm{N} 1 \cdots \mathrm{O} 2\end{array}$ & $2.7541(18)$ & $2.737(9)$ & $2.730(8)$ & $2.723(8)$ & $2.725(9)$ & 0.029 \\
\hline $\begin{array}{l}\mathrm{N} 1 \mathrm{H} 1 \cdots \mathrm{O} 3^{\mathrm{ii}} \\
\mathrm{N} 1 \cdots \mathrm{O} 3\end{array}$ & $3.202(2)$ & $3.042(6)$ & $2.972(6)$ & $2.928(6)$ & $2.925(7)$ & 0.277 \\
\hline \multicolumn{7}{|c|}{ Hydrogen bonds formed within the $\beta$ sheet-like layers } \\
\hline $\begin{array}{c}\mathrm{N} 1 \mathrm{H} 2 \cdots \mathrm{O} 3^{\mathrm{iii}} \\
\mathrm{N} 1 \cdots \mathrm{O} 3\end{array}$ & $2.7223(19)$ & $2.674(9)$ & $2.657(8)$ & $2.649(8)$ & $2.624(9)$ & 0.098 \\
\hline $\begin{array}{c}\mathrm{N} 1 \mathrm{H} 3 \cdots \mathrm{O} 2^{\mathrm{iv}} \\
\mathrm{N} 1 \cdots \mathrm{O} 2\end{array}$ & $2.7913(18)$ & $2.755(6)$ & $2.731(6)$ & $2.708(6)$ & $2.713(7)$ & 0.078 \\
\hline $\begin{array}{l}\mathrm{N} 2 \mathrm{H} 6 \cdots \mathrm{O} 1^{\mathrm{v}} \\
\mathrm{N} 2 \cdots \mathrm{O} 1\end{array}$ & $2.9567(18)$ & $2.861(6)$ & $2.814(5)$ & $2.783(5)$ & $2.772(5)$ & 0.185 \\
\hline \multicolumn{7}{|c|}{$\mathrm{C}-\mathrm{H} \cdots \mathrm{O}$ hydrogen bonds } \\
\hline $\begin{array}{c}\mathrm{C} 1 \mathrm{H} 4 \cdots \mathrm{O}^{\mathrm{v}} \\
\mathrm{C} 1 \cdots \mathrm{O} 1\end{array}$ & $3.214(2)$ & $3.160(7)$ & $3.133(7)$ & $3.119(7)$ & $3.125(7)$ & 0.089 \\
\hline $\begin{array}{c}\mathrm{C} 1 \mathrm{H} 5 . \cdots \mathrm{O} 1^{\mathrm{vi}} \\
\mathrm{C} 1 \cdots \mathrm{O} 1\end{array}$ & $3.348(2)$ & $3.252(9)$ & $3.207(8)$ & $3.180(8)$ & $3.160(9)$ & 0.188 \\
\hline $\begin{array}{c}\mathrm{C} 3 \mathrm{H} 8 \cdots \mathrm{O} 2^{\mathrm{vii}} \\
\mathrm{C} 3 \cdots \mathrm{O} 2\end{array}$ & $3.593(2)$ & $3.356(7)$ & $3.265(6)$ & $3.221(6)$ & $3.202(7)$ & 0.391 \\
\hline $\begin{array}{c}\mathrm{C} 3 \mathrm{H} 8 \cdots \mathrm{O}^{\mathrm{vi}} \\
\mathrm{C} 3 \cdots \mathrm{O} 3\end{array}$ & $3.603(2)$ & $3.382(8)$ & $3.308(7)$ & $3.282(7)$ & $3.251(7)$ & 0.352 \\
\hline \multicolumn{7}{|c|}{$\mathrm{C}=\mathrm{O} \cdots \mathrm{C}=\mathrm{O}$ interactions } \\
\hline $\mathrm{C} 2=\mathrm{O} 1 \cdots \mathrm{C} 2=\mathrm{O} 1^{\mathrm{iv}}$ & $3.573(2)$ & $3.480(6)$ & $3.435(6)$ & $3.404(6)$ & $3.395(6)$ & 0.178 \\
\hline $\mathrm{C} 4=\mathrm{O} 2 \cdots \mathrm{C} 2=\mathrm{O} 1^{\mathrm{i}}$ & $3.274(2)$ & $3.105(7)$ & $3.014(7)$ & $2.939(7)$ & $2.909(7)$ & 0.365 \\
\hline $\mathrm{C} 4=\mathrm{O} 2 \cdots \mathrm{C} 4=\mathrm{O} 2^{\text {vii }}$ & $3.405(2)$ & $3.127(7)$ & $3.022(7)$ & $2.976(7)$ & $2.952(7)$ & 0.453 \\
\hline
\end{tabular}

Symmetry codes: (i) $1-x, 1-y,-z$; (ii) $1+x, \frac{1}{2}-y$, $\frac{1}{2}+z$; (iii) $1+x, y, 1+z$; (iv) $1-x,-\frac{1}{2}+y, \frac{1}{2}-z$; (v) $1-x, \frac{1}{2}+y, \frac{1}{2}-z$; (vi) $x, \frac{1}{2}-y, \frac{1}{2}+z$; (vii) $-x, 1-y,-z$.

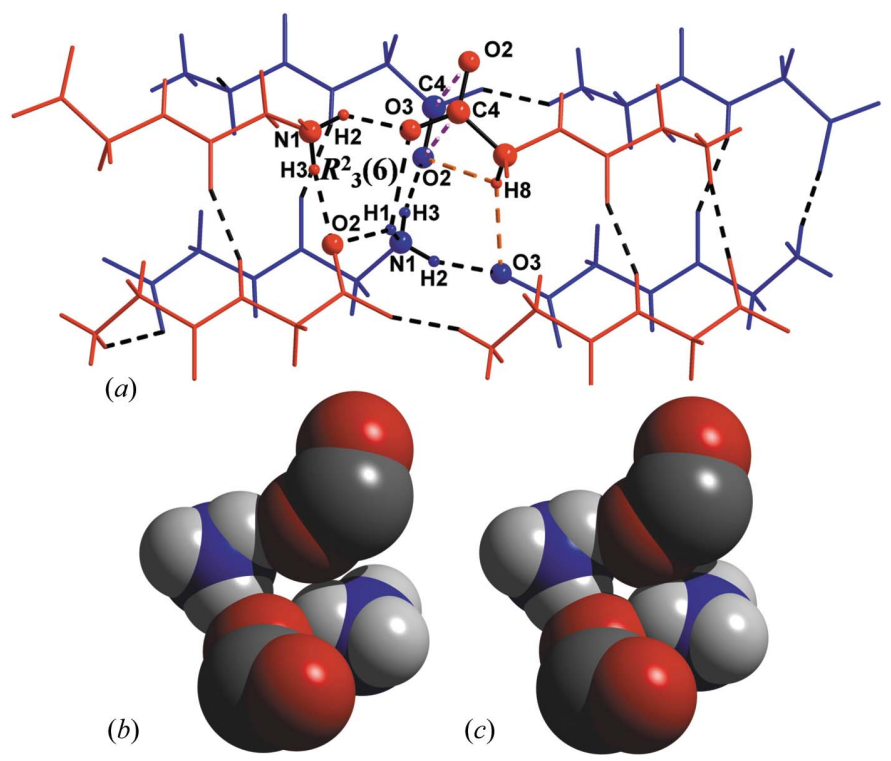

Figure 3

Ball-and-stick/wire model showing interactions between layers of GLYGLY molecules as viewed $(a)$ perpendicular to the $(10 \overline{1})$ plane. Molecules in the upper and lower layers are coloured red and blue, respectively. $R_{3}^{2}(6)$ ring motifs between layers of GLYGLY molecules are shown. Black and orange dotted lines represent $\mathrm{NH} \cdots \mathrm{O}$ and $\mathrm{CH} \cdots \mathrm{O}$ hydrogen bonds, respectively, while pink dotted lines represent weak $\mathrm{C}=\mathrm{O} \cdots \mathrm{C}=\mathrm{O}$ interactions. Space-filling plots of $R_{3}^{2}(6)$ ring motifs at $(b)$ ambient pressure and (c) $4.7 \mathrm{GPa}$ are shown, drawn at the same scale and direction with only the ammonium and carboxyl groups involved in the formation of the rings shown. The colour scheme is the same as that in Fig. 2. stabilization of $\alpha$ helices and $\beta$ sheets (Maccallum et al., 1995). In $\alpha$-GLYGLY $\mathrm{C}=\mathrm{O} \cdots \mathrm{C}=\mathrm{O}$ interactions occur within the $\beta$ sheet-like layers between adjacent carbonyl groups (Fig. 2a). A typical $d(\mathrm{O} \cdots \mathrm{C})$ distance of $c a 3.6 \AA$ is reported for the average of 12 sets of secondary structural features (Maccallum et al., 1995). This value is in agreement with that measured for $\alpha$-GLYGLY under ambient pressure conditions [3.573 (2) Å]. Carboxyl-carboxyl and carboxyl-carbonyl interactions are formed between the GLYGLY layers. One such interaction occurs between pairs of $\mathrm{C} 4=\mathrm{O} 2$ bonds and is aligned in an antiparallel fashion; another, $\mathrm{C} 4=\mathrm{O} 2 \cdots \mathrm{C} 2=\mathrm{O} 1$, forms a sheared parallel motif (Allen et al., 1998).

\subsection{Effect of pressure on the unit-cell dimen- sions}

$\alpha$-GLYGLY was found to be stable to $5.4 \mathrm{GPa}$. However, the refined parameters of data collected at $5.4 \mathrm{GPa}$ were imprecise and therefore only structural data to $4.7 \mathrm{GPa}$ are reported here and used for comparison with the ambient pressure structure.

The response of the lattice parameters of $\alpha$ GLYGLY to pressure is anisotropic, with the largest principal component of the strain tensor (Hazen \& Finger, 1982) formed between the $\beta$ sheet-like planes, making an angle of $69.22(6)^{\circ}$ with the $(10 \overline{1})$ plane. The most compressible unit-cell dimension (Fig. 6) is the $a$ axis which decreases by $11.2 \%$, with the $b$ and $c$ axes reducing by 3.8 and $3.6 \%$, respectively, between ambient pressure and $5.4 \mathrm{GPa}$. The $\beta$ angle also decreases by $6.61^{\circ}$. Between ambient pressure and 5.4 GPa the volume of $\alpha$ GLYGLY decreases by $15.2 \%$; most of the compression takes place in the first $1.4 \mathrm{GPa}$, with a reduction in volume of $8.0 \%$. The gradient of the graph of pressure versus volume (Fig. 6c) decreases markedly under pressure just before the break-up of the crystal.

\subsection{Conformational analysis of the $\beta$ sheet motif}

The structural analogy between the structure of the layers in $\alpha$-GLYGLY and $\beta$ sheet motifs found in proteins was referred to above. Similar observations have been applied to $N$-formylL-Met-L-Val trihydrate (Chatterjee \& Parthasarathy, 1984) and L-His-Gly chloride (Steiner, 1997), which form parallel and antiparallel $\beta$ sheet-like motifs, respectively.

In antiparallel $\beta$ sheets the conformational angles $\mathrm{C}(\mathrm{O})-$ $\mathrm{N}(\mathrm{H})-\mathrm{C}_{\alpha}-\mathrm{C}(\mathrm{O}) \quad(\varphi)$ and $\mathrm{N}(\mathrm{H})-\mathrm{C}_{\alpha}-\mathrm{C}(\mathrm{O})-\mathrm{N}(\mathrm{H}) \quad(\psi)$ adopt typical values of -139 and $+135^{\circ}$ under ambient pressure conditions, although these values can vary somewhat (Voet \& Voet, 1995). In $\alpha$-GLYGLY these torsion angles can be defined $\varphi 1, \psi 1, \varphi 2$ and $\psi 2$, leading from the free ammonium end to the free carboxyl end, and correspond to the torsion angles about $\mathrm{N} 1-\mathrm{C} 1, \mathrm{C} 1-\mathrm{C} 2, \mathrm{~N} 2-\mathrm{C} 3$ and $\mathrm{C} 3-\mathrm{C} 4$ (Table 3). $\varphi 1$ is therefore 'unconventional' in the sense that it 
cannot be defined within the dipeptide molecule; rather, we use the carboxyl $\mathrm{O} 3$ atom to which $\mathrm{N} 1$ is hydrogen bonded (labelled $\mathrm{O} 3{ }^{\mathrm{iii}}$ in Tables 2 and 3). At ambient pressure, $\varphi 1$ and $\psi 1$ are -154.77 (10) and $-152.38(13)^{\circ}$, respectively, while $\varphi 2$ and $\psi 2$ measure $-155.06(14)$ and $169.70(14)^{\circ}$, respectively.

These torsion angles, particularly for $\psi$, are quite far from those expected for an antiparallel $\beta$ sheet structure. This is not surprising because of the flexibility of the glycine residues, in particular the ammonium end, which is primarily optimized for hydrogen bonding within the structure. Nevertheless, on increasing the pressure to $4.7 \mathrm{GPa}$ the molecules remain fairly inflexible with both $\varphi 1$ and $\psi 1$ increasing by +3.4 and $+1.1^{\circ}$, respectively, while $\varphi 2$ and $\psi 2$ decrease and increase by only -3.5 and $+2.2^{\circ}$, respectively.

\subsection{NH $\cdots$ O hydrogen bonds}

The variation in hydrogen-bonding parameters between ambient pressure and $4.7 \mathrm{GPa}$ is shown in Table 2. Since all $\mathrm{H}$ atoms were placed geometrically, $\mathrm{N} \cdots \mathrm{O}$ distances were used to quantify the relative compressibility of the hydrogen bonds. The most compressible of the $\mathrm{NH} \cdots \mathrm{O}$ hydrogen bonds is the longer interaction in the bifurcated $\mathrm{N} 1 \mathrm{H} 1 \cdots \mathrm{O} 2 / \mathrm{O} 3$ hydrogen bond, which acts between the $\beta$ sheet-like layers. The shorter of these bonds, $\mathrm{N} 1 \mathrm{H} 1 \cdots \mathrm{O} 2$, is the least compressible hydrogen bond in the system. The next most compressible hydrogen bond, $\mathrm{N} 2 \mathrm{H} 6 \cdots \mathrm{O} 1$, is the interaction between neighbouring peptide groups which act within the $\beta$ sheet-like layers (Fig. 2a). In a study of the mean geometries of $\mathrm{C}-$ $\mathrm{H} \cdots \mathrm{O}$ and $\mathrm{N}-\mathrm{H} \cdots \mathrm{O}$ hydrogen-bonding interactions in parallel and antiparallel $\beta$ sheets (Fabiola et al., 1997), the mean distance for this particular $\mathrm{N}-\mathrm{H} \cdots \mathrm{O}$ hydrogen bond is $2.89 \AA$, that is, slightly shorter than observed in $\alpha$-GLYGLY at ambient pressure. This interaction runs in the same direction as the second largest component of the strain tensor, which is parallel to $\mathbf{b}$ and is shown as a red arrow in Fig. 2(a).

$\mathrm{N} 1 \mathrm{H} 2 \cdots \mathrm{O} 3$ shortens more than $\mathrm{N} 1 \mathrm{H} 3 \cdots \mathrm{O} 2$, even though the latter is the longer bond at ambient pressure. $\mathrm{N} 1 \mathrm{H} 2 \cdots \mathrm{O} 3$ decreases in length to 2.624 (9) $\AA$ at 4.7 GPa. This distance is very short: the shortest $\mathrm{NH} \cdots \mathrm{O}$ (carboxylate) in-

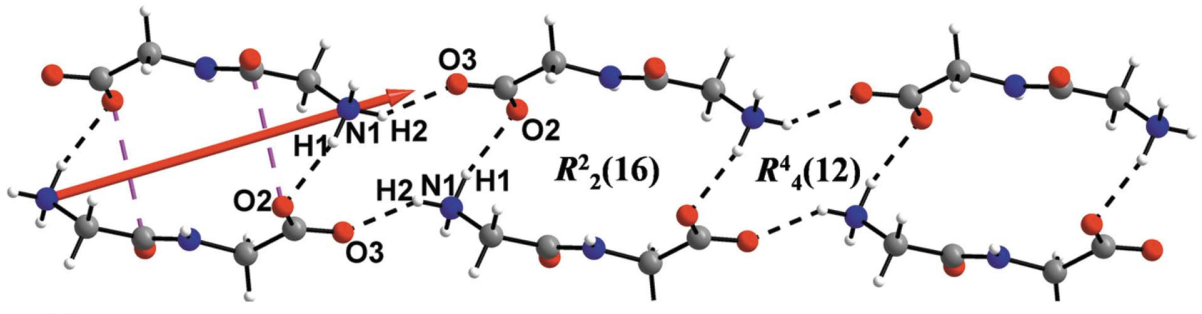

(a)
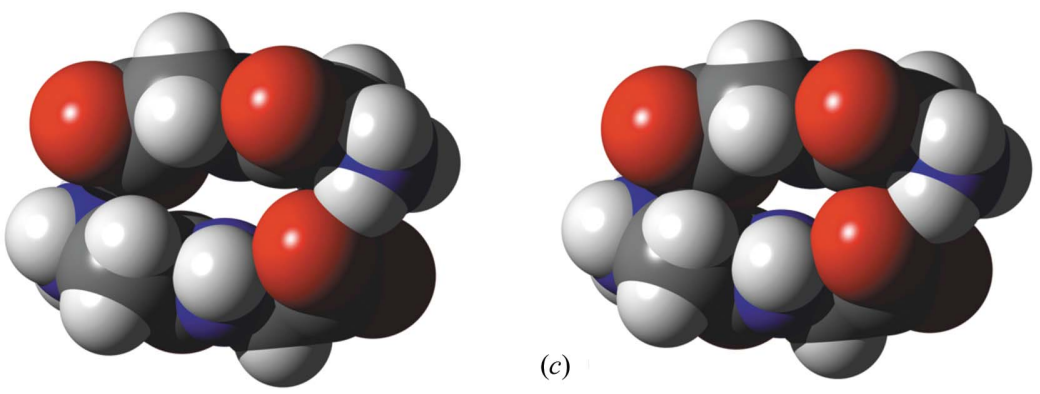

(b)

(c)
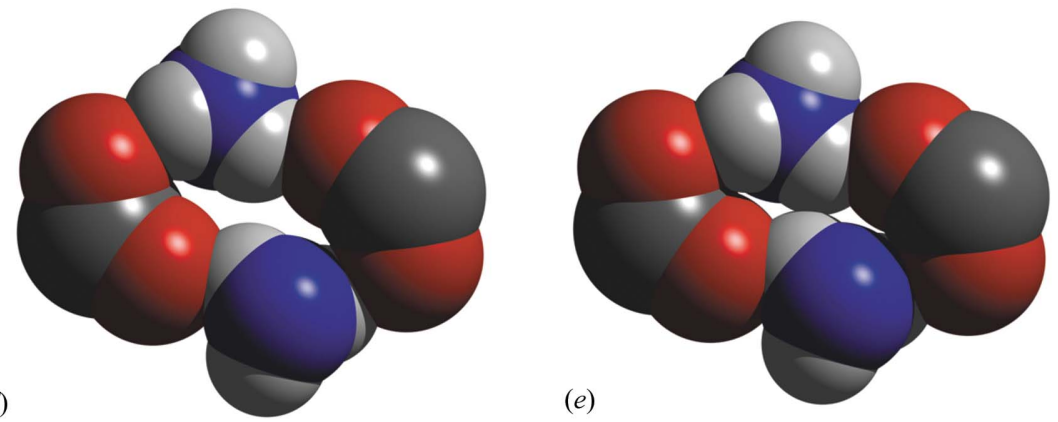

(e)

teraction to be observed in ambientpressure structures of peptides occurs in L-valyl-L-phenylalanine, measuring 2.649 (5) § (Görbitz, 2002). Short NH...O hydrogen bonds have also been observed in Lcystine [2.690 (18) Å; Moggach, Allan, Lozano-Casal \& Parsons, 2005] at $3.7 \mathrm{GPa}$ and $\epsilon$-glycine at $4.3 \mathrm{GPa}$ [2.59 (4) А̊; Dawson et al., 2005].

\section{5. $\mathrm{CH} \cdots \mathrm{O}$ hydrogen bonds}

The most compressible of the $\mathrm{CH}$... O hydrogen-bonding interactions is the bifurcated system, $\mathrm{C} 3 \mathrm{H} 8 \cdots \mathrm{O} 2 / \mathrm{O} 3$, formed between the $\beta$ sheet-like layers. The $\mathrm{C}$. . O distances in this interaction decrease in length by 0.39 and $0.35 \AA$ between ambient pressure and 4.7 $\mathrm{GPa}$, that is, substantially more than any of the $\mathrm{NH}$.. O bonds.

C1H4...O1 decreases by a relatively modest $0.089 \AA$ between ambient pressure and $4.7 \mathrm{GPa}$, measuring 3.125 (7) $\AA$ at $4.7 \mathrm{GPa}$. In antiparallel $\beta$ sheets the mean C...O distance for this type of interaction is typically $3.27 \AA$ (Fabiola et al., 1997), with minimum and maximum values under ambient conditions of 2.91 and $3.50 \AA$,
Figure 4

(a) Ball-and-stick model showing the $R_{2}^{2}(16)$ and $R_{4}^{4}(12)$ ring motifs under ambient pressure conditions between GLYGLY layers. Weak $\mathrm{C}=\mathrm{O} \cdots \mathrm{C}=\mathrm{O}$ interactions are drawn as pink dotted lines in the far left motif, while NH...O hydrogen bonds are drawn as black dotted lines. The largest component of the strain tensor is drawn as a red arrow in (a). Space-filling plots for $R_{2}^{2}(16)$ and $R_{4}^{4}(12)$ motifs in $\alpha$ GLYGLY at ambient pressure $(b)$ and $(d)$, and $4.7 \mathrm{GPa}(c)$ and $(e)$ are drawn at the same scale and direction. For clarity, only the ammonium and carboxyl groups are included for comparison in $(d)$ and (e). Note that voids within $R_{2}^{2}(16)$ and $R_{4}^{4}(12)$ ring motifs close up on increasing pressure. The colour scheme is the same as that in Fig. 2. 
Table 3

Torsion angles $\varphi$ and $\psi\left({ }^{\circ}\right)$ in $\alpha$-GLYGLY as a function of pressure.

For numbering refer to text.

\begin{tabular}{lrr}
\hline Pressure $(\mathrm{GPa})$ & 0 & \multicolumn{1}{l}{} \\
\hline $\mathrm{O}^{\mathrm{i}}-\mathrm{N} 1-\mathrm{C} 1-\mathrm{C} 2(\varphi 1)$ & $-154.77(10)$ & $-151.4(4)$ \\
$\mathrm{N} 1-\mathrm{C} 1-\mathrm{C} 2-\mathrm{N} 2(\psi 1)$ & $-152.38(13)$ & $-151.3(6)$ \\
$\mathrm{C} 2-\mathrm{N} 2-\mathrm{C} 3-\mathrm{C} 4(\varphi 2)$ & $-155.06(14)$ & $-158.6(6)$ \\
$\mathrm{N} 2-\mathrm{C} 3-\mathrm{C} 4-\mathrm{O} 3(\psi 2)$ & $169.70(14)$ & $171.9(5)$ \\
\hline
\end{tabular}

Symmetry code: (i) $1+x, y, 1+z$.

respectively ( $3.50 \AA$ being the cut-off distance used in the study).

\section{6. $\mathrm{C}=\mathrm{O} \cdots \mathrm{C}=\mathrm{O}$ interactions}

The least compressible of the $\mathrm{C}=\mathrm{O} \cdots \mathrm{C}=\mathrm{O}$ interactions, $\mathrm{C} 2=\mathrm{O} 1 \cdots \mathrm{C} 2=\mathrm{O} 1$, acts within the $\beta$ sheet-like layers and decreases in length by $0.178 \AA$ between ambient and $4.7 \mathrm{GPa}$. This interaction runs in the same direction as the second largest component of the strain tensor and its compression is comparable to that of $\mathrm{N} 2 \mathrm{H} 6 \cdots \mathrm{O} 1$, which also acts within the layers, between adjacent peptide groups (reducing in length by $0.185 \AA$ ). The most compressible $\mathrm{C}=\mathrm{O} \cdots \mathrm{C}=\mathrm{O}$ interaction is formed between carboxyl groups, $\mathrm{C} 4=\mathrm{O} 2 \cdots \mathrm{C} 4=\mathrm{O} 2$, with $d(\mathrm{C} \cdots \mathrm{O})$ decreasing by $0.453 \AA$. This interaction, which measures 2.952 (7) $\AA$ at $4.7 \mathrm{GPa}$ acts between the layers and is the most compressible interaction in the structure.

The last of the $\mathrm{C}=\mathrm{O} \cdots \mathrm{C}=\mathrm{O}$ interactions, $\mathrm{C} 4=\mathrm{O} 2 \cdots \mathrm{C} 2=\mathrm{O} 1$, acts between adjacent carboxyl and carbonyl groups and decreases by $0.365 \AA$ between ambient pressure and $4.7 \mathrm{GPa}$. This interaction, like that of $\mathrm{C} 4=\mathrm{O} 2 \cdots \mathrm{C} 4=\mathrm{O} 2$, acts between the layers and is the shortest of the three $\mathrm{C}=\mathrm{O} \cdots \mathrm{C}=\mathrm{O}$ interactions at $4.7 \mathrm{GPa}$, measuring 2.909 (7) А.

\section{Discussion}

\subsection{Restrained refinement of GLYGLY at high pressure}

Intramolecular bonds are expected to lengthen as intermolecular interactions strengthen with pressure. In paracetamol, for example, the shortening of an intermolecular $\mathrm{OH} \cdots \mathrm{O}(\mathrm{O}=\mathrm{C})$ hydrogen bond is accompanied by a small elongation of the $\mathrm{C}=\mathrm{O}$ bond $(0.023 \AA$ at $4 \mathrm{GPa}$; Boldyreva, 2003). Studies of 2-methyl-1,3-cyclopentanedione, dimedone and 1,3-cyclohexanedione also reveal similar variations with pressure (0.02 $\AA$ at $3 \mathrm{GPa}$; Katrusiak, 1992). However, these changes are very small and in most high-pressure structure determinations are within experimental error. In a recent $a b$ initio study on the effect of pressure on pentaerythritol tetranitrate at $23 \mathrm{GPa}$, changes in calculated bond lengths on compression showed that $\mathrm{C}-\mathrm{C}$ bonds decrease by $0.05 \AA$, while $\mathrm{CH}$ and $\mathrm{CO}$ bonds decreased by only $0.01 \AA$ (Brand, 2005). The largest change in bond angle in this study was $3.7^{\circ}$, while the largest change in torsion angle was $11^{\circ}$.
In high-pressure crystallography, particularly when applied to low-symmetry crystal systems, shading by the pressure cell restricts the volume of reciprocal space that can be sampled. This leads to low data completeness and low data-to-parameter ratios during refinement. During refinement of the highpressure crystal structures reported here intramolecular bond distances and angles (but not the torsion angles) were restrained to their ambient pressure values in order to alleviate these refinement problems. While such restraints can be justified below about $10 \mathrm{GPa}$, this approximation is likely to become less accurate at higher pressures.

\subsection{Anisotropic compression of $a$-GLYGLY}

In previous pressure studies of L-serine-I and hexagonal Lcystine we have ascribed trends in the relative compressibility of $\mathrm{CH} \cdots \mathrm{O}$ and $\mathrm{NH} \cdots \mathrm{O}$ hydrogen bonds to the closing up of voids within $R$-type ring motifs, which exist under ambient pressure conditions. These voids are conveniently visualized in $\alpha$-GLYGLY by comparing space-filling plots of ring motifs between ambient pressure and $4.7 \mathrm{GPa}$.

In $\alpha$-GLYGLY there are five $R$-type ring motifs: all of these contain voids at the ring-centres, and all become smaller as pressure increases. These $R$ motifs can be split into two cate-
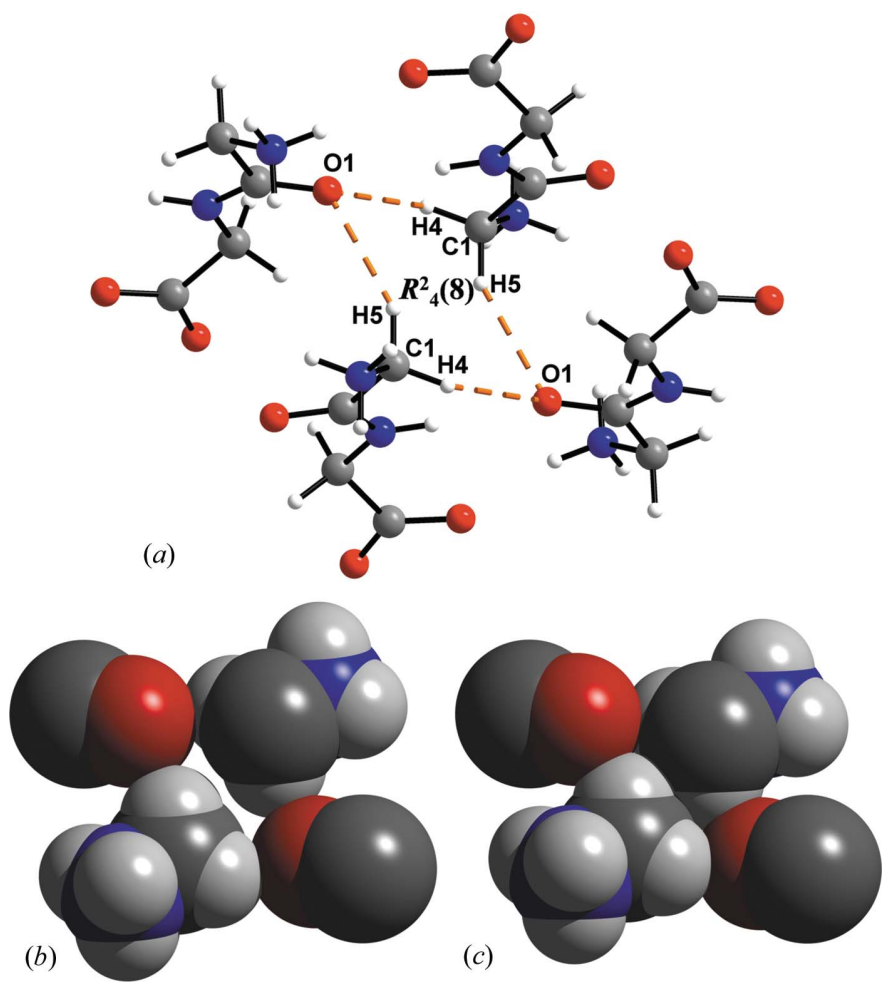

Figure 5

(a) Ball-and-stick model showing the formation of $R_{4}^{2}(8)$ ring motifs via $\mathrm{CH} \cdots \mathrm{O}$ hydrogen bonds acting between layers of GLYGLY molecules, $\mathrm{CH}$... O hydrogen bonds are drawn as orange dotted lines. Space-filling plots of $R_{4}^{2}(8)$ ring motifs at (b) ambient pressure and (c) $4.7 \mathrm{GPa}$ are shown, drawn at the same scale and direction. In both $(b)$ and $(c)$, only those atoms involved in the formation of the ring, carbonyl $\mathrm{C}$ atoms and ammonium groups are shown for clarity. The colour scheme is the same as that in Fig. 2. 
gories, those within the GLYGLY layers $\left[R_{2}^{2}(10)\right.$ and $\left.R_{4}^{4}(18)\right]$, and those between the layers $\left[R_{3}^{2}(6), R_{2}^{2}(16)\right.$ and $\left.R_{4}^{4}(12)\right]$. The largest voids formed within the layers are those at the centre of the $R_{4}^{4}(18)$ ring motifs (Fig. 2) and these are far from being completely closed at $4.7 \mathrm{GPa}$. Increasing pressure would be expected to close these voids still further, but $\mathrm{N} 1 \mathrm{H} 2 \cdots \mathrm{O} 3$ measures 2.624 (9) $\AA$ at $4.7 \mathrm{GPa}$, and in amino acids attainment of an $\mathrm{NH}$. . O distance as short as this preludes a phase transition. This is consistent with the break-up of the crystal which ensues above $4.7 \mathrm{GPa}$. Of the three hydrogen bonds involved in the formation of the $R_{4}^{4}(18)$ rings, the most compressible is $\mathrm{N} 2 \mathrm{H} 6 \cdots \mathrm{O} 1$, which is also the longest of the three at ambient pressure. Very small voids can also be observed within $R_{2}^{2}(10)$ ring motifs which also close up on increasing pressure to $4.7 \mathrm{GPa}$.

Between the layers, the closure of voids can also be observed within $R_{4}^{4}(12), R_{3}^{2}(6)$ and $R_{2}^{2}(16)$ ring motifs (Fig. $3 b / c$, $4 b / c$ and $4 d / e$, respectively). This is achieved by a sliding action of the layers across each other and moving closer together, rather than direct compression of $\mathrm{N} 1 \mathrm{H} 1 \cdots \mathrm{O} 2$, which is the least compressible of the $\mathrm{NH} \cdots \mathrm{O}$ hydrogen bonds formed. The combination of the sliding of the layers and their movement closer together accounts for the direction of the largest component of the strain tensor, which is illustrated in Fig. 4(a). As the layers are compressed together the hydrogen bond about $\mathrm{H} 1$ becomes more bifurcated (Fig. $3 b / c$ ); as in the case for $\mathrm{N} 2 \mathrm{H} 6 \cdots \mathrm{O} 1$, described above, this occurs through the compression of a relatively long hydrogen bond (N1H1 . O O 3$)$.

The compression of the layers leads to shortening of two $\mathrm{C}=\mathrm{O} \cdots \mathrm{C}=\mathrm{O}$ interactions. $\mathrm{C} 4=\mathrm{O} 2 \cdots \mathrm{C} 4=\mathrm{O} 2$ decreases by $0.453 \AA$, while $\mathrm{C} 4=\mathrm{O} 2 \cdots \mathrm{C} 2=\mathrm{O} 1$ compresses to become the shortest of its type in $\alpha$-GLYGLY, although still substantially longer $[2.909$ (7) $\AA$ ] than the shortest value observed under ambient pressure conditions [2.521 (2) $\AA$; Kapplinger et al., 1999].

Our work on amino acids has shown that compression is accompanied by an increase in the number and strength of $\mathrm{CH} \cdots \mathrm{O}$ contacts. Hence the void in the $R_{4}^{2}(8)$ ring motifs formed between $\mathrm{C} 1 \mathrm{H} 4 \cdots \mathrm{O} 1$ and $\mathrm{C} 1 \mathrm{H} 5 \cdots \mathrm{O} 1$, which act between the $\beta$ sheet-like layers, closes up on increasing pressure (Figs. $5 b$ and $c$ ). The longest $\mathrm{CH} \cdots \mathrm{O}$ hydrogen bond is the bifurcated interaction $\mathrm{C} 3 \mathrm{H} 8 \cdots \mathrm{O} 2 / 3$, which experiences the greatest shortening (Table 2).

To summarize, compression of $\alpha$-GLYGLY proceeds via the reduction in void sizes. Voids close in such a way as to decrease the distances of stabilizing interactions such as hydrogen

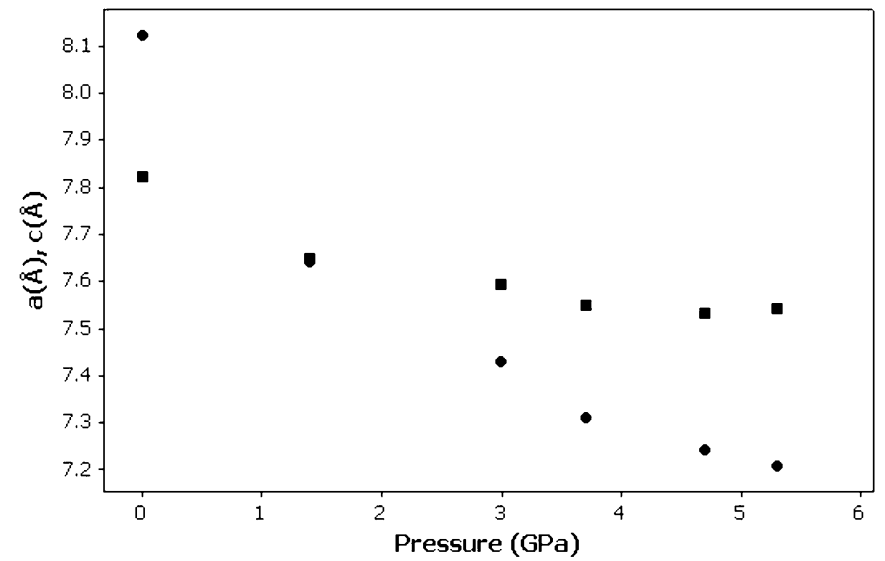

(a)

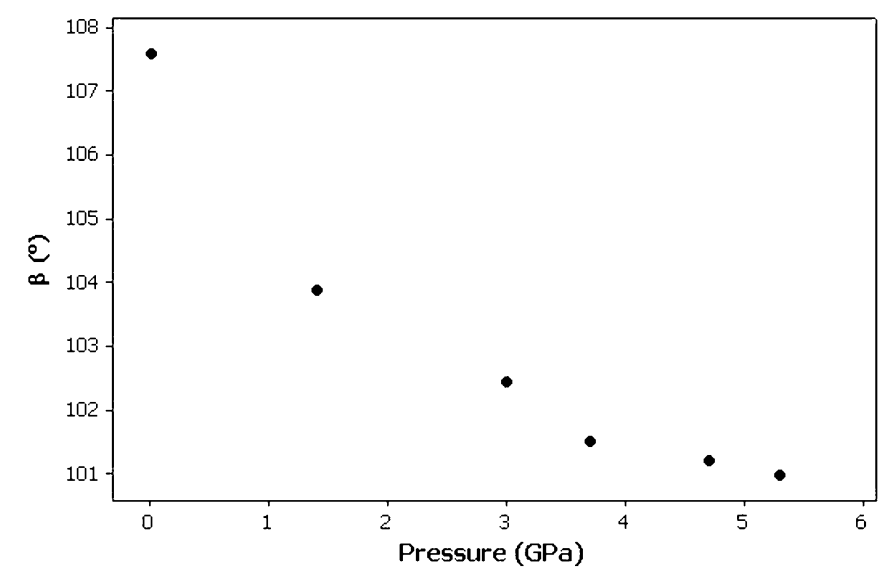

(c)

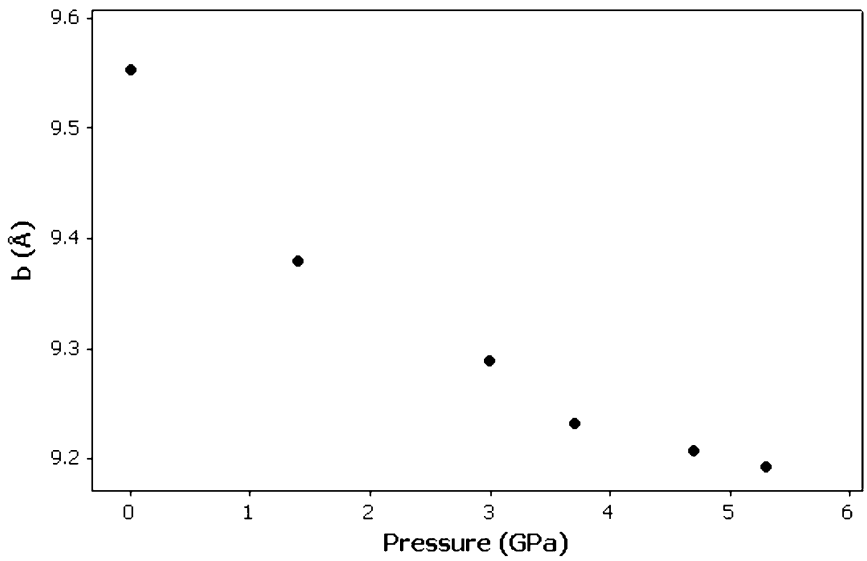

(b)

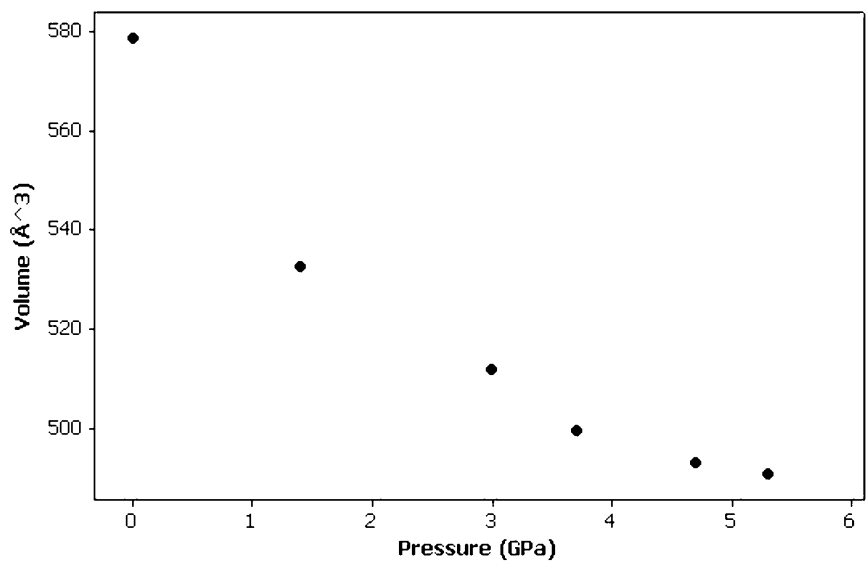

(d)

Figure 6

Variation of lattice parameters $a, b, c(\AA), \beta\left(^{\circ}\right)$ and volume $\left(\AA^{3}\right)$ of $\alpha$-GLYGLY as a function of pressure (GPa). The variation of $a$ and $c$ are shown on the same graph, with black circles and squares, respectively. 
bonds and dipolar contacts, but once a contact has become very short (in this case $\mathrm{N} 1 \mathrm{H} 2 \cdots \mathrm{O} 3$ ), the crystal begins to break-up, presumably as a result of a phase change. The largest reductions in interaction distances tend to occur for those contacts which are longest at ambient pressure. In $\alpha$ GLYGLY these longer interactions are formed between the $\beta$ sheet-like layers and it is understandable therefore that the direction of greatest compression lies in the same direction.

\subsection{Hirshfeld surface analysis}

Hirshfeld surfaces are constructed by partitioning space within a crystal structure into regions where the electron density from a sum of spherical atoms (the promolecule) dominates over the sum of the electron density of the crystal (the procrystal; McKinnon et al., 2004). In this study, Hirshfeld surfaces were constructed using the program CrystalExplorer (Wolff et al., 2005). Fig. 7 shows the distance external to the surface to the nearest nucleus in another molecule $\left(d_{e}\right)$ mapped onto the surface in two different ranges $0.68-2.31 \AA$ [labelled (i)] and 1.1-1.5 $\AA$ [labelled (ii)]. Each surface is shown in three orientations at ambient pressure (top row, $a-c$ ) and $4.7 \mathrm{GPa}$ (bottom row, $d-f$ ).

In Fig. 7(a)(i)-(f)(i), red regions on the surface arise from short values of $d_{e}$ (i.e. hydrogen-bond acceptors), while flat green regions around the ammonium group and peptide N2H6 ... 1 hydrogen bond correspond to hydrogen-bond donors. Blue regions correspond to long contacts. On increasing the pressure to $4.7 \mathrm{GPa}$, there are fewer blue regions (longer contacts) and more red regions (short contacts), consistent with the general shortening of contacts at high pressure [Fig. $7 a(\mathrm{i})-f(\mathrm{i})$ ]. The decrease in lengths of $\mathrm{NH} \cdots \mathrm{O}$ hydrogen bonds from the ammonium moiety and the peptide hydrogen bond can be seen in Figs. $7(a)(\mathrm{i}) /(d)(\mathrm{i})$ and $(b)(i) /(e)(i)$, as an increase in the size of the red regions labelled 1 and 2. The yellow regions labelled 3 and 4 in Fig. $7(a)(\mathrm{i})$ and $(b)(\mathrm{i})$, which are derived from $\mathrm{C} 1 \mathrm{H} 5 \cdots \mathrm{O} 1$ and

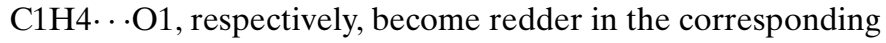
regions of Figs. 7(d)(i) and $(e)(\mathrm{i})$, indicating a shortening of these contacts at $4.7 \mathrm{GPa}$. The substantial shortening of the bifurcated hydrogen bond $\mathrm{C} 3 \mathrm{H} 8 \cdots \mathrm{O} 2 / \mathrm{O} 3$ appears in regions 5 [Fig. $7 a(\mathrm{i}) / d(\mathrm{i})]$ and 6 [Fig. $7 c(\mathrm{i}) / f(\mathrm{i})]$.

In Fig. 7(a)(i)-(c)(i), blue regions on the surfaces correspond to voids in the structure. As these voids become smaller at high pressure the surfaces become greener. For example, the darkest blue region, labelled 7 in Fig. 7(a)(i), corresponds to voids in $R_{2}^{2}(16)$ ring motifs ( $c f$ Fig. $4 b$ ) between the $\beta$ sheetlike layers in the structure. Region 8 [Fig. $7 b(\mathrm{i})$ ] corresponds to voids in the middle of $R_{4}^{4}(18)$ ring motifs; the reduction in the size of this void can be seen in the corresponding region of Fig. 7(e)(i). Notably, this void appears on the surface beside the $\mathrm{C} 3-\mathrm{H} 7$ bond, the only one of its type not involved in the formation of a $\mathrm{CH} \cdots \mathrm{O}$ hydrogen bond, although a contact is formed between $\mathrm{C} 3 \mathrm{H} 7 \cdots \mathrm{O} 1$, this contact is long, even at 4.7 GPa (3.311 $\AA$ ). This contact, although it is long, does appear on the surface in Fig. 7(c)(i) labelled 9. The region becomes markedly more yellow at $4.7 \mathrm{GPa}$ [Fig. $7 f(\mathrm{i})]$, again clearly representing the compression between the layers.

The region in Fig. 7(c)(i) labelled 10 is a close contact between two $\mathrm{H}$ atoms attached to the $\mathrm{CH}_{2}$ groups of adjacent ammonium moieties between layers. This region becomes markedly more yellow at $4.7 \mathrm{GPa}$ showing the compression of non-polar side groups of the dipeptide toward each other on increasing pressure.

The compression of the $\mathrm{C}=\mathrm{O} \cdots \mathrm{C}=\mathrm{O}$ groups is not nearly as clear on the surfaces in Figs. 7(a)(i)-(f)(i). In part this is (a)
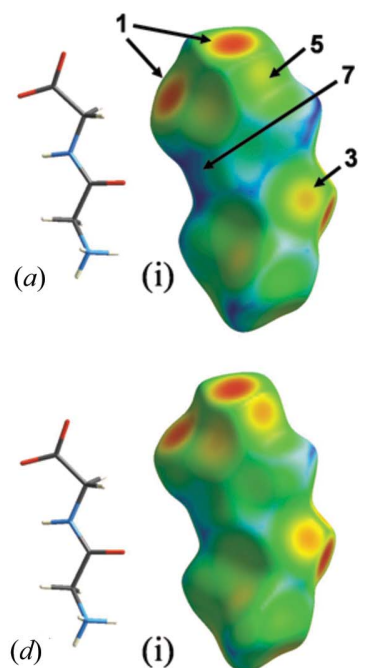

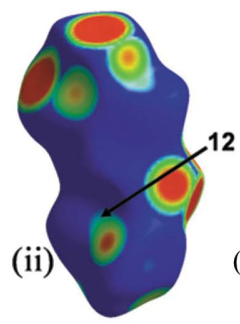

(b)

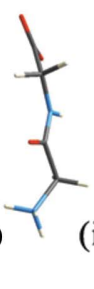

(i)

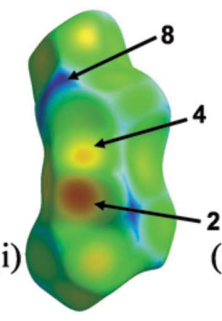

(ii)

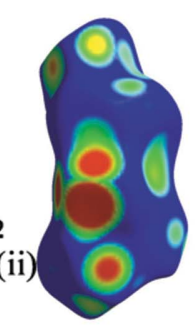

(c)

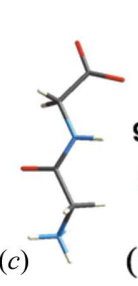

(i)

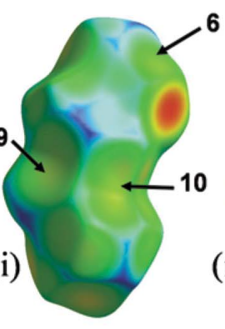

(ii)

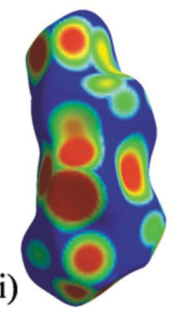

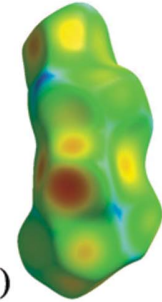

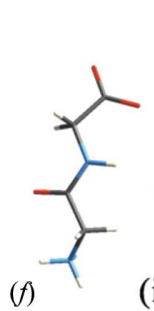

(f)

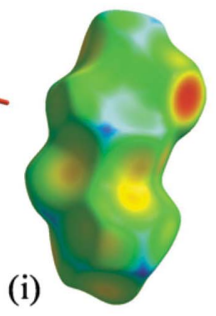

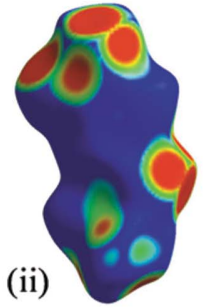

(e)

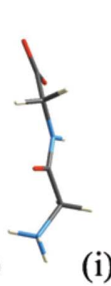

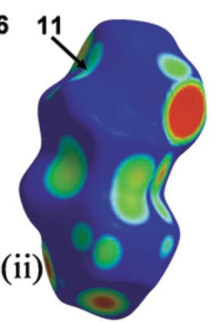

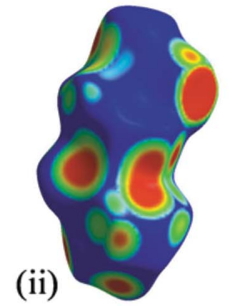

Figure 7

The Hirshfeld surface of GLYGLY at $(a)-(c)$ ambient temperature and pressure, and $(d)-(f) 4.7 \mathrm{GPa}$. The surfaces at both ambient pressure and 4.7 GPa

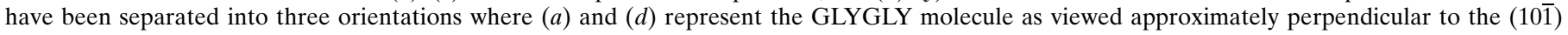
plane. Both $(b)$ and $(e)$, and $(c)$ and $(f)$ represent $90^{\circ}$ increment rotations about the vertical axis from $(a)$ and $(d)$. In comparing both the ambient pressure and 4.7 GPa structures, all hydrogen bonds have been normalized to neutron distances $(\mathrm{C}-\mathrm{H}=1.083$ and $\mathrm{N}-\mathrm{H}=1.009 \AA)$. Surfaces have been mapped over two ranges between $[a(\mathrm{i})-f(\mathrm{i})] d_{e}, 0.68-2.31 \AA$ and $[a(\mathrm{ii})-f(\mathrm{ii})] 1.1-1.5 \AA$. The molecules beside the surfaces have been added for clarity; for numbers refer to the text. Colour scheme: $\mathrm{C}$ grey, $\mathrm{N}$ blue, $\mathrm{O}$ red and $\mathrm{H}$ white. 
because they are masked by much shorter contacts between $\mathrm{NH} \cdots \mathrm{O}$ and $\mathrm{C}=\mathrm{O}$. These contacts can be made clearer by mapping $d_{e}$ on the surface over a shorter range [see Fig. 7a(ii)$f($ ii) $]$. This not only enhances the $\mathrm{C}=\mathrm{O} \cdots \mathrm{C}=\mathrm{O}$ interactions, but makes the increase in strength of $\mathrm{CH} \cdots \mathrm{O}$ and $\mathrm{NH} \cdots \mathrm{O}$ contacts much clearer. However, the regions in which void closure takes place become much more difficult to see, and therefore both sets of surfaces mapped over different ranges are included in Fig. 7.

$\mathrm{C} 4=\mathrm{O} 2 \cdots \mathrm{C} 4=\mathrm{O} 2$, the most compressible interaction, appears in region 11 [Fig. $7 c$ (ii)]. The increase in size of the blue/green region in Fig. 7(f)(ii) corresponds to the shortening of this interaction on increasing pressure. The final $\mathrm{C}=\mathrm{O} \cdots \mathrm{C}=\mathrm{O}$ interaction, $\mathrm{C} 4=\mathrm{O} 2 \cdots \mathrm{C} 2=\mathrm{O} 1$, is the shortest of the three $\mathrm{C}=\mathrm{O} \cdots \mathrm{C}=\mathrm{O}$ interactions at $4.7 \mathrm{GPa}$, and can be seen in region 12 [Fig. $7 a$ (ii)]. Again, the size of this region increases in Fig. 7(d)(ii) and demonstrates the closing up of voids within $R_{2}^{2}(16)$ ring motifs between the layers (Fig. $4 b / c$ ). Notably, this is the shortest of the $\mathrm{C}=\mathrm{O} \cdots \mathrm{C}=\mathrm{O}$ interactions at $4.7 \mathrm{GPa}$ and thus accounts for why the $\mathrm{C} 4=\mathrm{O} 2 \cdots \mathrm{C} 2=\mathrm{O} 1$ contact is markedly clearer in appearance on the surface than that formed by $\mathrm{C} 4=\mathrm{O} 2 \cdots \mathrm{C} 4=\mathrm{O} 2$.

\subsection{Fingerprint plots}

A fingerprint plot is a plot of $d_{e}$ against $d_{i}$ (the distance from the surface to the nearest atom in the molecule itself). It can be used to encode information on overall packing characteristics (Fig. 8). The number of longer contacts decreases as the points at larger values of $d_{e}$ become less frequent at $4.7 \mathrm{GPa}$ : these interactions are formed across the voids within the $R$ type ring motifs. The overall shortening of these longer contacts is related to the fingerprint plots by a decrease in the maximum values of $d_{e}$ between ambient pressure $(2.303 \AA)$ and $4.7 \mathrm{GPa}(2.196 \AA)$. The two long spikes in both plots represent $\mathrm{NH} \cdots \mathrm{O}$ hydrogen bonds, specifically the shortest $d_{e}$ value at $4.7 \mathrm{GPa}$ is caused by $\mathrm{N} 1 \mathrm{H} 2 \cdots \mathrm{O} 3$, the shortest of the $\mathrm{NH} \cdots \mathrm{O}$ hydrogen bonds at this pressure. In previous studies, such as that of L-cystine, $\mathrm{NH}$. . O hydrogen bonds have been

(a)

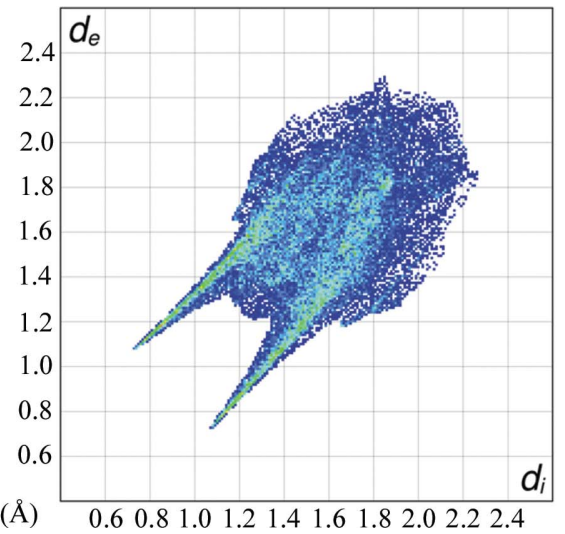

(b)

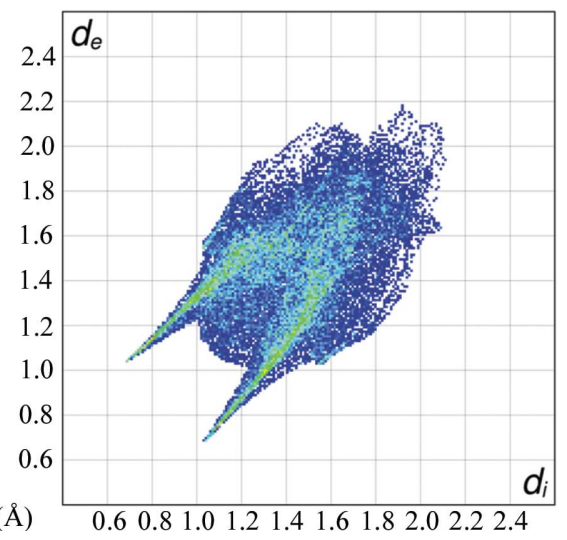

Figure 8

Two-dimensional fingerprint plots for $\alpha$-GLYGLY at (a) ambient temperature and pressure and (b) 4.7 GPa. found to be less compressible than 'softer' $\mathrm{CH} \cdots \mathrm{O}$ interactions. This is represented clearly in the fingerprint plot, as the $\mathrm{NH}$.. O spikes become less pronounced as the rest of the plot moves toward the origin.

\section{Conclusions}

We have described the effect of pressure on the crystal structure of $\alpha$-GLYGLY. The structure can be considered to consist of layers of GLYGLY molecules which stack perpendicular to the (101) direction, which are made up of $R_{2}^{2}(10)$ and $R_{4}^{4}(18)$ ring motifs constructed via $\mathrm{NH} \cdots \mathrm{O}$ hydrogen-bonding interactions. Ring motifs are also formed between layers, again by $\mathrm{NH} \cdots \mathrm{O}$ hydrogen-bonding interactions in $R_{4}^{4}(12), R_{2}^{2}(16)$ and $R_{3}^{2}(6)$ ring motifs. The arrangement of GLYGLY molecules within each layer resembles that of an antiparallel $\beta$ sheet motif observed in protein structures, where in $\alpha$ GLYGLY the molecules in the $\beta$ sheet motif are linked through $\mathrm{NH} \cdots \mathrm{O}$ hydrogen bonds rather than conventional covalent amide links. The conformational changes in the pressure regime studied are quite modest and the same might be expected of $\beta$ sheets.

The structure was found to be stable to $5.4 \mathrm{GPa}$, although structural data were only reported to $4.7 \mathrm{GPa}$. $\alpha$-GLYGLY undergoes anisotropic compression in which the principal effect is to compress voids in the structure, particularly those between the layers. This compression continued until, at $5.4 \mathrm{GPa}$, the sample began to break apart and no structural data could be extracted. At $4.7 \mathrm{GPa}$ the length of $\mathrm{N} 1 \mathrm{H} 2 \cdots \mathrm{O} 3$ decreased in size to the minimum distance usually observed under ambient pressure conditions ( $c a 2.6 \AA$ ) for this type of interaction and it is possible that relief of these close contacts drives the phase transition.

The compression of both $\mathrm{NH} \cdots \mathrm{O}$ and soft $\mathrm{CH} \cdots \mathrm{O}$ interactions are also described using Hirshfeld surfaces. These clearly show the reduction in the sizes of voids and a decrease in length of $\mathrm{CH} \cdots \mathrm{O}, \mathrm{NH} \cdots \mathrm{O}$ and $\mathrm{C}=\mathrm{O} \cdots \mathrm{C}=\mathrm{O}$ interactions with increasing pressure, both between and within the layers. Hirshfeld surfaces are an effective means to gain an overall view of the environment of molecules at increasing compression in an anisotropic fashion.

We would like to thank Dr Josh McKinnon for his help with the program CrystalExplorer, the EPSRC and The University of Edinburgh for funding.

\section{References}

Allen, F. H. (2002). Acta Cryst. B58, 380-388. 
Allen, F. H., Baalham, C. A., Lommerse, J. P. M. \& Raithby, P. R. (1998). Acta Cryst. B54, 320-329.

Allen, F. H. \& Motherwell, W. D. S. (2002). Acta Cryst. B58, 407-422.

Bernal, J. D. (1931). Z. Kristallogr. Kristallgeom. Kristallphys. Kristallchem. 78, 363-369.

Bernstein, J., Davis, R. E., Shimoni, L. \& Chang, N.-L. (1995). Angew. Chem. Int. Ed. Engl. 34, 1555-1573.

Betteridge, P. W., Carruthers, J. R., Cooper, R. I., Prout, K. \& Watkin, D. J. (2003). J. Appl. Cryst. 36, 1487.

Boldyreva, E. V. (2003). J. Mol. Struct. 647, 159-179.

Boldyreva, E. V., Ivashevskaya, S. N., Sowa, H., Ahsbahs, H. \& Weber, H.-P. (2004). Dokl. Phys. Chem. 396, 111-114.

Boldyreva, E. V., Kolesnik, E. N., Drebushchak, T. N., Ahsbahs, H., Beukes, J. A. \& Weber, H.-P. (2005). Z. Kristallogr. 220, 58-65.

Brand, H. V. (2005). J. Phys. Chem. B, 109, 13668-13675.

Bruker-Nonius (2002). SMART. Bruker-Nonius, Madison, Wisconsin, USA.

Bruker-Nonius (2004a). SAINT, Version V7.12A. Bruker-Nonius, Madison, Wisconsin, USA.

Bruker-Nonius (2004b). APEX-II, Version V1. Bruker-Nonius, Madison, Wisconsin, USA.

Chatterjee, A. \& Parthasarathy, R. (1984). Int. J. Pept. Protein Res. 24, 447-452.

Crystal Impact (2004). DIAMOND, Version 3.0. Crystal Impact GbR, Postfach 1251, 53002 Bonn, Germany. http://www.crystalimpact.com/diamond.

Dawson, A., Allan, D. R., Belmonte, S. A., Clark, S. J., David,W. I. F., McGregor, P. A., Parsons, S., Pulham, C. R. \& Sawyer, L. (2005). Cryst. Growth Des. 5, 1415-1427.

Dawson, A., Allan, D. R., Clark, S. J., Parsons, S. \& Ruf, M. (2004). J. Appl. Cryst. 37, 410-416.

Derewenda, Z. S., Lee, L. \& Derewenda, U. (1995). J. Mol. Biol. 252, 248-262.

Desiraju, G. R. \& Steiner, T. (1999). The Weak Hydrogen Bond in Structural Chemistry and Biology. IUCr Monographs on Crystallography No. 9. Oxford Univerity Press.

Fabiola, G. F., Krishnaswamy, S., Nagarajan, V. \& Pattabhi, V. (1997). Acta Cryst. D53, 316-320.

Farrugia, L. J. (1999). J. Appl. Cryst. 32, 837-838.

Girard, E., Kahn, R., Mezouar, M., Dhaussy, A.-C., Lin, T., Johnson, J. E. \& Fourme, R. (2005). Biophys. J. 88, 3562-3571.

Görbitz, C. H. (1989). Acta Cryst. B45, 390-395.

Görbitz, C. H. (2002). Acta Cryst. B58, 512-518.
Hazen, R. M. \& Finger, L. W. (1982). Comparative Crystal Chemistry, pp. 80-82. New York: John Wiley and Sons.

Hughes, E. W. \& Moore, W. J. (1949). J. Am. Chem. Soc. 71, 26182623.

Jeffrey, G. A. \& Maluszynska, H. (1982). Int. J. Biol. Macromol. 3, 173-185.

Kapplinger, I., Keutel, H. \& Jager, E. G. (1999). Inorg. Chim. Acta, 291, 190-206.

Katrusiak, A. (1990a). High Press. Res. 4, 496-498.

Katrusiak, A. (1990b). Acta Cryst. B46, 246-256.

Katrusiak, A. (1992). J. Mol. Struct. 269, 329-354.

Katrusiak, A. (2004). High-Pressure Crystallography, edited by A. Katrusiak \& P. F. McMillan, pp. 513-520. Dordrecht: Kluwer Academic Publishers.

Katrusiak, A. \& Nelmes, R. J. (1986). J. Phys. C Solid State Phys. 19, L765-L772.

Kvick, Å., Karaghouli, A. R. \& Koetzle, T. F. (1977). Acta Cryst. B33, 3796-3801.

Maccallum, P. H., Poet, R. \& Milner-White, J. E. (1995). J. Mol. Biol. 248, 361-373.

Merrill, L. \& Bassett, W. A. (1974). Rev. Sci. Instrum. 45, 290294.

McKinnon, J. J., Spackman, M. A. \& Mitchell, A. S. (2004). Acta Cryst. B60, 627-668.

Moggach, S. A., Allan, D. R., Lozano-Casal, P. \& Parsons, S. (2005). J. Synchrotron Rad. 12, 590-597.

Moggach, S. A., Allan, D. R., Morrison, C. A., Parsons, S. \& Sawyer, L. (2005). Acta Cryst. B61, 58-68.

Moggach, S. A., Allan, D. R., Parsons, S., Sawyer, L. \& Warren, J. E. (2005). J. Synchrotron Rad. 12, 598-607.

Parsons, S. (2004). SHADE. The University of Edinburgh, Scotland.

Piermarini, G. J., Block, S., Barnett, J. D. \& Forman, R. A. (1975). J. Appl. Phys. 46, 2774-2780.

Sheldrick, G. M. (1997). XP. University of Göttingen, Germany.

Sheldrick, G. M. (2004). SADABS. University of Göttingen, Germany.

Spek, A. L. (2003). J. Appl. Cryst. 36, 7-13.

Steiner, T. (1997). Acta Cryst. C53, 730-732.

Voet, D. \& Voet, J. G. (1995). Biochemistry, 2nd ed. New York: Wiley.

Wolff, S. K., Grimwood, D. J., McKinnon, J. J., Jayatilaka, D. \& Spackman, M. A. (2005). CrystalExplorer, Version 1.5. University of Western Australia. http://www.Theochem.uwa.edu.au/crystal_explorer/. 